\title{
Establishing a K-12 Nanotechnology Program for Teacher Professional Development
}

\author{
Chih-Kuan Lee, Tsung-Tsong Wu, Pei-Ling Liu, and Shihkuan Hsu
}

\begin{abstract}
Interest in science and engineering starts early. Opportunities need to be available for students to nourish their budding curiosity. In order to provide educational opportunities on the cutting edge of advanced technology, the National Science Council, Taiwan, R.O.C., established a nanotechnology program for K-12 teachers. Supported by the National Science Council and the Ministry of Education, the K-12 Nanotechnology Program was led by engineering faculty at National Taiwan University, Taipei, Taiwan, R.O.C. In about two years, 169 schools participated in five regional programs. The teachers began the program knowing little about nanotechnology. Survey results showed that participating teachers' attitudes and interests toward learning about science and technology increased through the involvement in the project. Issues about sustaining the effort and reaching out to students are also discussed.
\end{abstract}

Index Terms-Engineering faculty, K-12 education, nanotechnology, program development, teacher professional development.

\section{INTRODUCTION}

$\mathbf{T}$ ECHNOLOGICAL development requires trained personnel. Having skilled and dedicated workers is important to technological advancement. Students choosing engineering as a major in the past two decades, however, have decreased in technologically advanced countries like the United States [1]. For example, undergraduate engineering enrollment dropped from nearly 450000 students in 1982 to just over 350000 in 2000. To increase technological development over the last 25 years, the government in Taiwan has funded many economic development, technology transfer, and human resource development programs, including the Industrial Technology Research Institute (ITRI), the Institute for Information Industry (III), and the Hsinchu Science-Based Industrial Park (HSIP). The K-12 Nanotechnology Program is one recent example.

To develop a capable work force, a nation needs long-term planning to encourage interest and knowledge in advanced technology in its youngsters. Nanotechnology, an emerging field that will impact many areas of science and technology, was seen as a catalyst for transformation ${ }^{1}$ [2]. To accelerate the research and development of nanotechnology, the National Science Council of Taiwan launched the National Science and Technology Program for Nanoscience and Nanotechnology

Manuscript received August 2, 2005; revised October 16, 2005.

C.-K. Lee, T.-T. Wu, and P.-L. Liu are with the Institute of Applied Mechanics, National Taiwan University, Taipei, Taiwan 10617, R.O.C.

S. Hsu is with the Center for Teacher Education, National Taiwan University, Taipei, Taiwan 10617, R.O.C. (e-mail: skhsu@ntu.edu.tw).

Digital Object Identifier 10.1109/TE.2005.863429

${ }^{1}$ National Nanotechnology Initiative: Strategic Plan, available online at http://www.nano.gov/NNI_Strategic_Plan_2004.pdf

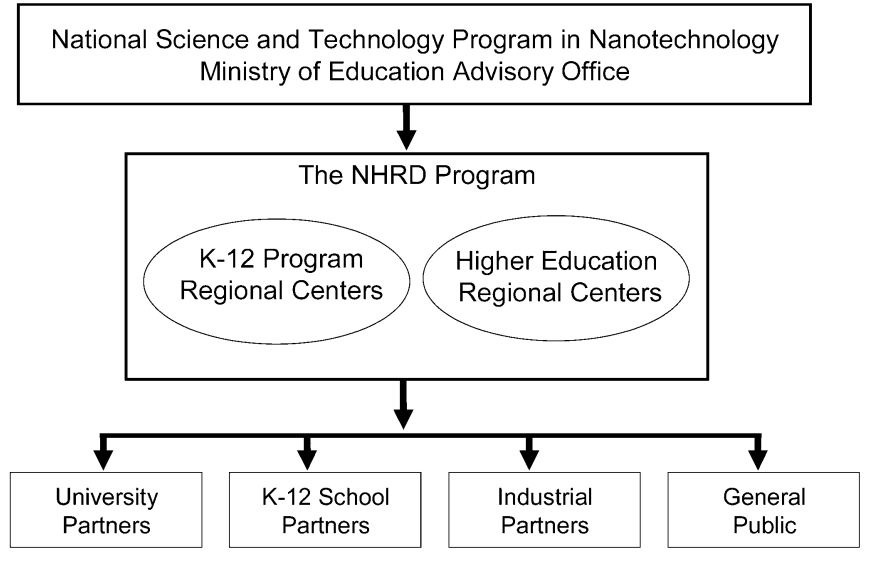

Fig. 1. Structure of the NHRD Program.

in $2002 .^{2}$ In addition to scientific research and technological development, the program included a human resource component. The Nanotechnology Human Resource Development (NHRD) program was established to undertake the task of education and teacher professional development. In cooperation with the Ministry of Education, NHRD included a K-12 Nanotechnology Program, which was established to prepare a future generation of researchers, engineers, designers, business leaders, and general public that support the development of advanced technology (Fig. 1). The K-12 Nanotechnology Program focused on introducing teachers to recent research and development in nanotechnology.

\section{K-12 NANOTEChNOLOGY PROGRAM}

The K-12 Nanotechnology Program was established in August 2002. The program was located at the Institute of Applied Mechanics, National Taiwan University, Taipei, Taiwan, R.O.C. [3]. The focus of the K-12 Nanotechnology Program was to provide teachers with information about nanotechnology and to develop material to inspire students to learn about advanced technology. There were two specific goals. The first goal was to overcome teachers' fear of learning about nanotechnology. The first goal was selected because most of the teachers were trained before the emergence of nanotechnology. The second goal was to help the teachers to develop the capacity to learn about new technology. The second goal was chosen because the knowledge about nanotechnology continues to grow and change. The teachers not only needed to learn about the current technology, but also needed to develop methods to learn about new technology.

${ }^{2}$ National Science and Technology Program for Nanoscience and Nanotechnology, available online at http://nano-taiwan.sinica.edu.tw/ProjectEn.asp?S=1 
The K-12 Nanotechnology Program was piloted in August 2002. At the beginning of the project, more than 40 teachers in seven Taipei schools participated. The teachers attended workshops by the experts in nanotechnology held at universities and research centers. After six months, the first group of teachers was able to transform difficult academic knowledge about nanotechnology into general science knowledge suitable for school curricula. They were able to produce lesson plans, instructional materials, tools and models, and hands-on activities. The results were demonstrated in a conference held in Taipei that was open to the teachers from all over Taiwan.

Some teachers who attended the conference expressed their interest in having similar programs in regions outside of Taipei. After the pilot program ended in 2003, the Ministry of Education established a full K-12 Nanotechnology Program in January 2004 to include five regional centers throughout Taiwan. Engineering professors at local universities in each region were recruited to lead the five regional centers. Through the expansion of the program, more schools and teachers were involved, and additional methods for dissemination were explored.

\section{IMPLEMENTATION AND MATERIAL DEVELOPMENT}

After the regional programs were funded, a main office was established at National Taiwan University to supervise the regional centers. The main program office issued general guidelines, but each center customized their activities for teacher training. For example, some regional centers collaborated with local science and technology museums for exhibits. Other centers tailored the workshops to teachers of different subjects and teaching levels. Communication across regions was achieved through the newsletter and website established by the main program office. As a result of the involvement of the engineering professors at various universities, the number of participating teachers, the amount of instructional material, and the variety of training activities all increased.

In about two years, 193 teachers from 169 schools participated in five regional programs. The participating teachers entered the program knowing little about nanotechnology. By the end, they were able to develop 224 lesson plans, write one book, and create one animated film. As a result of the collaboration between the universities and the schools, faculty from 17 universities participated. Five regional atomic force microscope (AFM) laboratories were established. One touring van was outfitted for school visits. The program included lectures and workshops, online courses, websites, and newsletters.

\section{A. Conducting Training Workshops for Teachers}

Workshops were the primary method for the teachers to learn about nanotechnology. During workshops, experts, professors, and experienced teachers in the pilot program gave talks and led hands-on activities. Topics included the science and technology background for nanotechnology and nano materials, such as "The Physical Phenomena of the Nano World," "Atoms, Molecular, and Nanotechnology," and "Preparation and Application of Nano Materials." Hands-on activities included topics such as "Making Carbon Nanocapsule and Carbon Nanotube Models,"
"Making Nano Solar Cells," and "The Application of Nano Particles in Biomedicine." Tours of laboratories and research facilities were arranged to provide an introduction to nanotechnology equipment unavailable to school teachers. Laboratory tours included the National Science Council Northern Region Micro-Electro-Mechanical Systems (MEMS) Research Center, and the Industrial Technology Research Institute (ITRI).

\section{B. Developing Lesson Plans and Instructional Materials}

After the workshops, the teachers met together to develop lessons and teaching materials. Most of the teachers preferred to work with colleagues in the same schools. The new teaching materials were discussed during regular meetings to make sure they were suitable for the level of students. Materials were evaluated in terms of the national curriculum at elementary and junior high schools. After being evaluated, the lessons were tested in trial classes. If the lessons were successful, they were shared with all the participating teachers. Successful lessons were presented at the second annual conference.

\section{Establishing an Exchange Network}

The K-12 Nanotechnology Program newsletter has been published since 2003. It contained updates on program activities, governmental policy regarding nanotechnology, news about technological development, interviews with researchers, stories from participating schools, and the experiences of classroom teachers. The newsletter was sent to participants and interested parties in academia, industry, government, and the general public.

In addition to the newsletter, a website called Electronic Knowledge Exchange Interface (http://www.nano.edu.tw) provided another channel of communication for the program participants. The website had an integrated interface for all regional centers to make it easier for the management and distribution of materials developed in the project. The website was password-protected so that the lesson plans and works-in-progress would not be released prematurely. This arrangement increased the productivity and efficiency of the teams in the five regions.

\section{Setting Up AFM Laboratories and the Touring Van}

To give the teachers and students experience with advanced nanotechnology equipment, the regional centers set up AFM laboratories at the participating universities. Starting in September 2004, each regional center received seed money to set up an AFM labroatory. They organized a three-year series of experimental courses for $\mathrm{K}-12$ participants. The initial effort focused on the set up of the laboratory, including purchasing the equipment and writing AFM manuals for $\mathrm{K}-12$ teachers and students.

In order to reach schools in remote areas, the main program office and the North Regional Center worked with the National Taiwan Science Education Center, Taipei, to build a demonstration van in 2004. The van included a DVD player that showed animated films made by the program office and programs from the Discovery Channel. Visitors could print out graphics of nano phenomena found in the nature. Hands-on activities included 
light penetration and reflection of buckyballs and carbon nanotubes. In addition, domestic products that used nano material, such as cloth, tiles, and tennis rocket nets, were displayed. An AFM machine was displayed and demonstrated by the support staff. The van was staffed by volunteer teachers from the pilot program. The staff provided on-site help when the van visited schools.

\section{E. Developing Teacher Training Materials}

To assemble instructional materials, lessons, pictures, and text created by the teachers were collected and published as a book. Beginning in 2002, the teachers started to write a three-part book titled Nanotechnology Symphony-Physics, Chemistry, and Biology [4]. This book was used as material for teacher training and introductory material about nanotechnology for the general public. This book contained introductory nanotechnology concepts, such as nano-size, nano-material, nano-catalyst, photonic crystal, microscopic technology, nano-biology, and various applications of nanotechnology. It contained six experiments designed to give students hands-on experience in a regular high school laboratory. The experiments included many topics, such as synthesis of aqueous ferrofluid, diffraction of laser beams with ferrofluid, and circulation of ferrofluid particles by $8-\mathrm{Hz}$ pulsewide movable circuit (PWMC) motor (Fig. 2). Some experiments were inspired by the K-12 instructional resource Nanoworld Cineplex from MRSEC on Nanostructured Material and Interfaces at the University of Wisconsin-Madison. ${ }^{3}$

\section{F. Developing Animated Films and Comic Books}

Special effort was made to design and develop material for students to learn about nanotechnology. In addition, teachers from one of the pilot primary schools developed a Flash animation. The animation was reworked with professional help, provided by the main program office and the North Regional Center. After more than one year of planning, designing, and rewriting, an animated nanotechnology film, entitled A Fantastic Journey for Nana and Nono, was produced by professional animators [5]. The animated film was released in July 2004. It introduced the basic theory of nanotechnology and applications for daily life from a child's perspective. A Fantastic Journey for Nana and Nono is a 15-minute-long film in the Chinese language with Chinese and English subtitles. The film has been shown in many countries and received widespread recognition. In August 2004, Thailand signed an international contract to use this animated film in their schools.

A comic book entitled Nano BlasterMan was also created for middle-school students [6]. It depicted the adventures of a superhero Nano BlasterMan, who could use the power of nanotechnology to fight evil (Fig. 3). The comic book was drawn by a professional illustrator, but the technical details were outlined by the engineering faculty at the main program office. The animated film and the comic book were examples of collaborative work initiated by teachers and completed with help from the program office.

\footnotetext{
${ }^{3}$ Available: http://mrsec.wisc.edu/Edetc/cineplex/index.html
}

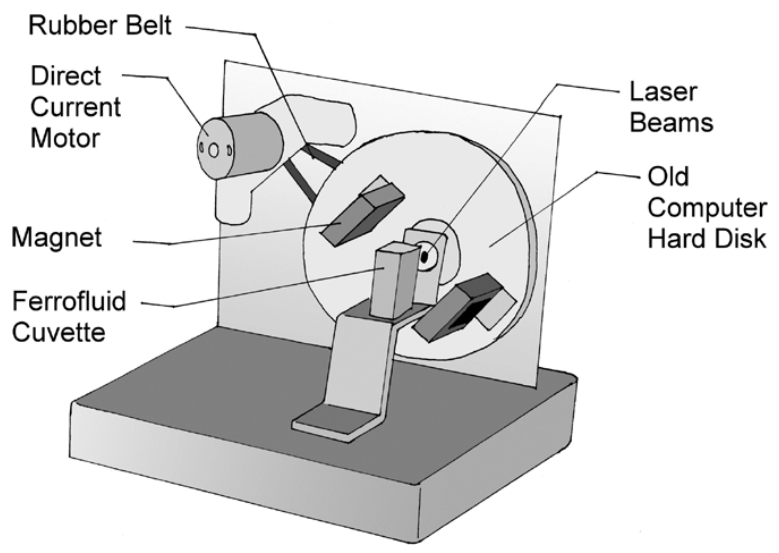

Fig. 2. Setup for the circulation of ferrofluid particles in the PWMC motor experiment.

\section{Teachers' AtTitudes AND Perceptions}

The K-12 Nanotechnology Program achieved substantial results in teacher professional development. Table I summarizes the results of a questionnaire that investigated teachers' growth in terms of their interest in science and technology, their feeling of support, and the constraints and opportunities during their involvement in the program. The questionnaire was distributed to participating teachers at the annual conference in November 2004. The results indicated that participating teachers' attitude and interest toward learning about science and technology had increased through the involvement in the project. About $96 \%$ of teachers felt that their interest in learning new technology ( = 4.42) has grown. About $85 \%$ felt they became more interested in learning about their own subjects $($ mean $=4.31)$ and even other content areas (mean $=4.17$ ). The support they received from the program office was satisfactory (mean $=4.27$ ), but the support from the school administrators (mean $=3.83$ ) and family (mean $=3.83$ ) was not as great. Most of the teachers did not feel financial burden $($ mean $=2.91)$ but felt time constraints (mean = 4.17) from participating in the program. Most of them felt that they have the opportunity to teach students the lessons developed in the program (mean $=4.26$ ).

In addition to teachers' attitudes, teachers' perceptions of their involvement in the program and difficulties in their participation are worth considering. The issues included teacher learning, time limitations, teacher burnout, and student outreach problems.

\section{A. Difficulties in Understanding Nanotechnology}

Not all the teachers were at an equal level of science learning and prepared to master the knowledge of this advanced technology when they started. In addition, during the program implementation, teachers differed in their interest in and acceptance of nanotechnology.

- $\quad$ The subject matter background: The knowledge base for nanotechnology has more relevance to teachers of science than social science and humanities and more to teachers of physics and chemistry than biology and earth science. Teachers with background other than physics and chemistry often found it difficult to understand and appreciate the subject of nanotechnology. 


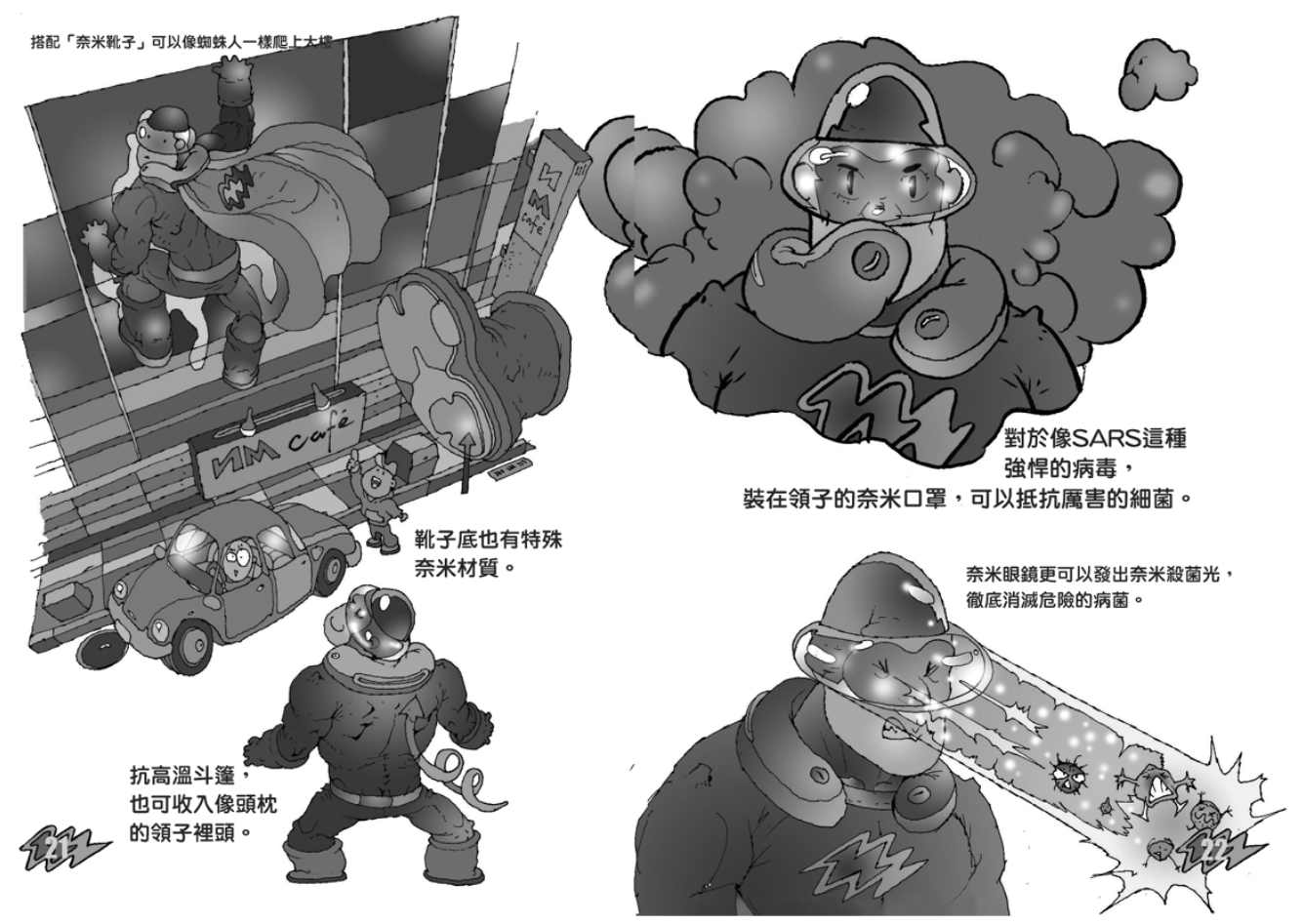

Fig. 3. Sample page of Nano BlasterMan.

TABLE I

PERCEPTIONS of TEACHERS Who PARTICIPATED IN THE K-12 NANOTECHNOLOGY PROGRAM

MEAN SD

\begin{tabular}{|c|c|c|}
\hline $\begin{array}{l}\text { 1. I became more interested in learning the subject I am } \\
\text { teaching }\end{array}$ & 4.31 & 0.72 \\
\hline 2. I became more interested in learning other subjects & 4.17 & 0.69 \\
\hline 3. I became more interested in new technology & 4.42 & 0.58 \\
\hline $\begin{array}{l}\text { 4. I am concerned about the impact of new technology on } \\
\text { society }\end{array}$ & 4.44 & 0.65 \\
\hline 5. I am satisfied with the help from my regional center & 4.27 & 0.68 \\
\hline 6. My effort was supported by administrators at my school & 3.83 & 1.11 \\
\hline 7. My effort was supported by colleagues at my school & 3.83 & 1.07 \\
\hline 8. I felt financial burden by attending the workshops & 2.91 & 1.35 \\
\hline 9. I felt time constraints when participating in the program & 4.17 & 0.84 \\
\hline 10.I have the opportunity to teach students the lessons I & 4.26 & 0.71 \\
\hline
\end{tabular}

developed

Note: $n=200$. Scale from strongly disagree to strongly agree was rated from 1-5.

- Grade level of teaching: Nanotechnology is a complicated subject. As a result, senior high school teachers had a better grasp of the information than junior high school teachers, who, in turn, were more capable of understanding it than elementary school teachers.

During the program, the best lecturers at workshops for teachers were not always experts or professors. For example, junior high school and elementary school teachers preferred listening to senior high school teachers explain nanotechnology over university professors. The lesson plans and materials developed by experienced senior high school teachers were often more beneficial to other teachers than engineering textbooks when teachers began to learn how to develop their own nanotechnology-related lessons. 


\section{B. Time and Energy Constraints and Administrative Support}

Most of the teachers indicated that the program offered great support to their learning of nanotechnology. Despite program support, many obstacles were encountered at local schools. The teachers who participated in this program often needed release time from their teaching or administrative duties to come to the workshops and to develop the lessons. Furthermore, they could not have participated in the nanotechnology program without the additional support of school administrators and colleagues.

A remedy for this problem was to make special efforts to win the acceptance of the educational community, including school teachers, principals, and government officers. In order to accomplish this goal, the engineering professors who led the regional programs had to reach out to the nontechnical members of the $\mathrm{K}-12$ community and the general public. For example, the directors had to ensure that award certificates from the Ministry of Education honoring professional contribution were presented to the teachers and to the schools. In addition, when animations and teaching materials were developed, the CDs were distributed to schools and teachers free of charge. The directors of the regional centers had to visit the principals of important cooperating schools, and important officers of the City Bureau of Education were invited to attend various meetings and ceremonies. All this public relations and public outreach work at the K-12 level was difficult for many engineering professors, especially for engineers who thought the program focus should be technical.

\section{Teacher Participation and Burnout}

After working for a year or longer on the K-12 Nanotechnology Program, many teachers felt exhausted. Their initial interest was challenged by the time and energy required to attend all the meetings, master the contents, and produce the lessons. They kept going for a while because of a sense of responsibility. At the end, after their materials were completed, they wanted to go back go their normal school life. The time and energy required took its toll on the participating teachers. Experienced teachers were crucial to the success of the program because they served as role models and offered assistance to new teachers, but many experienced teachers dropped out.

A remedy for teacher burnout would be to encourage the teachers to integrate what they created in their everyday school work. Several methods of integration were found helpful.

- The first way was to group teachers from the same school together and make nanotechnology a theme in their school-based curriculum. They could, therefore, allocate class time to teach the nanotechnology lessons they had developed.

- The second way was to identify topics related to the current curriculum and add related information while introducing the existing material.

- The third way was to develop supplemental materials to be used to fill in an assigned time block after school, or at the end of the semester. The content could be designed with greater flexibility to arouse students' interests in advanced technology.
- The fourth way was to design lessons for advanced programs in science and technology, which were usually for more advanced or gifted students.

With the limited time in regular curriculum, the fourth way was adopted more than the other three methods of integration.

\section{Finding Ways to Reach the Students}

The main focus of the K-12 Nanotechnology Program has been teacher training. Limited attention had been paid to students' learning. The main program office distributed a survey at the annual conferences to assess teachers' opinions about effective ways to reach the students. Suggestions included creating teaching and supplemental materials for students, providing hands-on experiments, creating animations, holding contests, building websites, and integrating nanotechnology into textbooks. Based on these suggestions, the main program office took several steps to produce materials for students, such as providing professional help in creating the animation film, illustrating the comic book, and building the touring van. In the future, greater effort will be placed on finding ways to help teachers reach the students.

\section{CONCLUSION}

The results of the K-12 Nanotechnology Program are encouraging. First, many teachers found renewed energy for learning, searching for information, discussing ideas, and creating materials for student learning. From knowing very little about nanotechnology to developing teaching materials, giving lectures to peer teachers, and writing text to introduce nanotechnology, the teachers found that they had to overcome many obstacles. The main obstacles were lack of confidence and lack of knowledge. Being in the program, they felt like they became students again. They learned about nanotechnology and wrote about what they learned. Many teachers said, "You can't write about it unless you're clear about it," and "You don't want to make mistakes when you are writing a book."

Second, many teachers gained confidence in themselves from the process of being engaged in intensive learning about a new technology. At the beginning of the program, most of the teachers felt that they knew nothing about nanotechnology. They did not believe that they would be able to understand complicated science and engineering concepts. "It is the professor's job, " one teacher said, "to understand current developments in nanotechnology, and then explain to us." After only six months, however, the teachers from the pilot program could present lessons and explain the concepts about nanotechnology in ways that impressed many of their peers. Numerous participants in later workshops were surprised that the pilot teachers knew so much about the theory and application of nanotechnology. According to the pilot teachers, after a while they no longer waited to be "spoon fed" by professors and experts. They became more confident and actively pursued knowledge and information about nanotechnology. For example, they took the initiative in checking the Internet for new developments, contacting national laboratories to arrange field trips, and making suggestions to the main program office about equipment purchases. 
Third, the teachers became reformers at their schools. The current national curriculum reform effort requires teachers at elementary and junior high schools to develop interdisciplinary curriculum that engages students in broader learning experiences. Many teachers in the K-12 Nanotechnology Program used the topic of nanotechnology to develop new curriculum for schools and to experiment with new ways of instruction in their own classes. At one school, a group of teachers worked as a team to develop school-based curriculum around nanotechnology. At another school, teachers worked together to explore the connection of nanotechnology with existing curriculum. At a third school, teachers provided supplemental material in their science and technology lessons for advanced students.

The collaboration between universities and schools in the K-12 Nanotechnology Program stimulated energy and creativity in the participating teachers. Teachers' behavior and beliefs have a great impact on children's learning [7], and students' attitudes and concepts are important to their learning [8]. If Taiwan were to develop a workforce capable of learning new technology and supporting advanced technology, it is important to help students become autonomous and confident learners. From the results of the K-12 Nanotechnology Program, one can see that professional development programs can help build a community of learners for cutting-edge science and engineering concepts.

\section{REFERENCES}

[1] G. C. Orsak, "K-12: Engineering's new frontier," IEEE Trans. Educ., vol. 46, no. 2, pp. 209-210, May 2003.

[2] C. K. Lee, M. K. Wu, and J. C. Yang, "A catalyst to change everything: MEMS/NEMS-A paradigm of Taiwan's nanotechnology program," $J$. Nanoparticle Res., vol. 4, pp. 377-386, 2002.

[3] T. T. Wu and C. K. Lee, "Taiwan: Ministry of Education and NTU implementing Taiwan Nanotechnology K-12 Education Program," Asia-Pac. Nanotechnol. Forum News J., vol. 2, no. 1, pp. 17-19, Jan. 2003.
[4] C. K. Lee and T. T. Wu, Eds., Nanotechnology Symphony-Physics, Chemistry, and Biology. Taipei, Taiwan, R.O.C.: Nat. Taiwan Univ. Press, 2004.

[5] Nanotechnology Human Resource Program, A Fantastic Journey for Nana and Nono. Taipei, Taiwan, R.O.C.: Nat. Taiwan Univ., 2004.

[6] Push, Nano BlasterMan. Taipei, Taiwan, R.O.C.: National Taiwan Univ. Press, 2005.

[7] M. Csikszentmihalyi and J. McCormack, "The influence of teachers," Phi Delta Kappan, vol. 67, no. 6, pp. 415-419, Feb. 1986.

[8] D. Marshall, M. Summer, and B. Woolnough, "Students' conceptions of learning in an engineering context," Higher Educ., vol. 38, no. 3, pp. 291-309, Oct. 1999.

Chih-Kuan Lee is a Professor at the Institute of Applied Mechanics at National Taiwan University, Taipei, Taiwan, R.O.C., and the Director General of the Department of Engineering and Applied Sciences at the National Science Council, Taiwan, R.O.C.

Tsung-Tsong Wu is a Professor at the Institute of Applied Mechanics at National Taiwan University, Taipei, Taiwan, R.O.C., and the Deputy Executive Secretary of the Science \& Technology Advisory Group at the Executive Yuan (the Cabinet).

Pei-Ling Liu is a Professor and the Director of the Institute of Applied Mechanics at National Taiwan University, Taipei, Taiwan, R.O.C., and an advisor to the Nanotechnology Division of the Ministry of Education Advisory Office.

Shihkuan Hsu is an Assistant Professor at the Center for Teacher Education at National Taiwan University, Taipei, Taiwan, R.O.C. 